MILITARY TECHNICAL COLLEGE Kobry Elkobbah - CAIRO - EGYPT

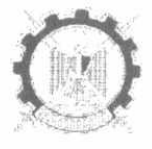

SECOND INTERNATIONAL CONFERENCE ON ELECTRICAL ENGINEERING NOVEMBER 23-25,

\title{
FUZZY LOGIC PERFORMANCE EVALUATION BASED ON CONTROL SYSTEM OF THREE AXIS GEOSYNCHRONOUS SATELLITE
}

\author{
Gamal M.I. Selim * Ayman Elshabrawy**
}

\section{ABSTRACT}

In the last decade fuzzy logic control became one of the most important fields in artificial intelligence and process control applications. Fuzzy logic controller is a rule based controller that uses information in the same manner as human experts and does not require the complex mathematics associated with classical control techniques.

This paper investigate the possibilities of applying fuzzy logic control system in both pitch and roll-yaw channels for a three axis geosynchronous satellite which required more accurate response compared to industrial processes.

\section{1-INTRODUCTION}

Fuzzy logic can deal with imprecise models. The central concept of fuzzy logic is the definition of sets in which the degree of belonging or degree of membership function represents, the degree by which certain element belongs to certain fuzzy set. This degree of membership is bounded between $[0,1]$ and it can be viewed as a generalization for the conventional set characteristic function which takes only the values 0 or 1 .

During the past decade fuzzy control has emerged as one of the most active and fruitful areas for research in the application of fuzzy set theory, in the industrial process which suffer result when controlled by conventional methods due to a lack of quantitative data regarding the input-output relations. Of course fuzzy control is based on fuzzy logic and so fuzzy logic controllers are based on fuzzy logic, which provides means for converting a linguistic control strategy based on expert knowledge into an automatic control strategy .

In this paper, the classical control schemes for the three axis stabilization satellite is replaced with fuzzy controller .

The paper has been organized in four section. A brief review of fuzzy set theory and fuzzy logic control has been discussed in section 2. The engagement model and the simulation result when using fuzzy logic are described in section three. The Conclusions obtained are given in section four.

* Ph.D., Dept. of radar and guidance, Egyptian armed force

** Msc, Egyptian armed force 


\section{2 - FUZZY SETS AND FUZZY LOGIC CONTROL}

Let $u$ be a collection of objects denoted generically by $\{u\}$ which could be discrete or continuous. $U$ is called the universe of discourse and $u$ represent the generic element of $\mathrm{U}$.

\section{2-1 Fuzzy Sets:}

Fuzzy set $F$ in a universe of discourse $U$ is characterized by a membership function $\mu_{\mathrm{f}}$ which take values in the interval $[0,1]$.

Namely $\mu_{\mathrm{f}}: U \longrightarrow[0,1]$ A fuzzy set may be viewed as generalization of the concept of an ordinary set whose membership Function takes only two values $\{0,1\}$.

Thus a fuzzy set $F$ in $U$ may be represented as a set of ordered pairs of generic element $u$ and its grade of membership function $f=\left\{\left(u, \mu_{f}(u)\right) \quad u \in U\right\}$

When $U$ is continuous a fuzzy set $F$ can be written concisely as

$$
f=\int_{u}^{\mu_{f}(u) / u d u} d u
$$

When $U$ is discrete a fuzzy set $f$ is represented as

$$
f=\sum_{i=1}^{n} \mu_{f}\left(u_{i}\right) / u_{i}
$$

Support of a fuzzy set $f$ is the crisp set of all points $S$ in $U$ such that $\mu_{f}(S)>0$. Cross over point is element $\mathrm{S}$ in $\mathrm{U}$ at which $\mu_{\mathrm{f}}(\mathrm{s})=0.5$, also fuzzy set whose support is a single point in $\mathrm{U}$ with $\mu_{\mathrm{f}}=1$ is referred to as fuzzy singleton.

Let $A$ and $B$ be two fuzzy sets in $U$ with membership function $\mu_{A}$ and $\mu_{B}$ respectively so the following properties are considered

\section{Union Operation:}

The membership function $\mu_{A} \cup B$ of the union $A \cup B$ is pointwise defined for all $u \in$ $U$ by $\mu_{A} \cup B(u)=\max .\left\{\mu_{A}(u), \mu_{B}(u)\right\}$.

\section{Intersection:}

The membership function $\mu_{A} \cap B$ of the intersection $A \cap B$ is pointwise defined for all $u \in U$ by $\mu_{A \cap B}(u)=\min .\left\{\mu_{A}(u), \mu_{B}(u)\right\}$.

\section{Complement:}

The $\mathrm{m}$ embership function $\mu_{\mathrm{A}}$ of the complement of fuzzy set $\mathrm{A}$ is pointwise defined for all $\mathrm{u} \in \mathrm{U}$ by $\mu_{-}(u)=1-\mu_{\mathrm{A}}(\mathrm{u})$ 
Proceedings of the $2^{\text {nd }}$ ICEENG conference, 23-25 Nov. 1999

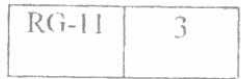

\section{Cartesian product:}

if $A_{1}, \ldots \ldots, A_{n}$ are fuzzy sets in $U_{1}, \ldots \ldots ., U_{n}$ respectively. The Cartesian

product of $A_{1}, \ldots \ldots, A_{n}$ is a fuzzy set in product space $U_{1} \times U_{2} \ldots \times U_{n}$ with membership function

$$
\mu_{A_{1} \times A_{2} \ldots . A_{n}}\left(u_{1}, u_{2}, \ldots ., u_{n}\right)=\min \left\{\mu_{A_{1}}\left(u_{1}\right), \ldots ., \mu_{A_{n}}\left(u_{n}\right)\right\}
$$

Or

$$
\mu_{A_{1 \times \ldots .} \times A_{n}}\left(u_{1}, u_{2}, \ldots . ., u_{n}\right)=\mu_{A_{1}}\left(u_{1}\right) \mu_{A_{2}}\left(u_{2}\right) \ldots \ldots \ldots \mu_{A_{n}}\left(u_{n}\right)
$$

\section{Fuzzy relation:}

A fuzzy relation $R$ from a set $X$ to a set $Y$ is a fuzzy subset of the Cartesian product $\mathrm{X} \times \mathrm{Y}$, and is expressed as

$$
R=\int_{X \times Y} \mu_{R}(x, y) /(x, y)
$$

More generally, for an $n$ array fuzzy relation $R$ which is a fuzzy subset of $x_{1}{ }^{*} x_{2}{ }^{*}$ .... $x_{n}$ We have

$$
R=\int x_{1} * x_{2} \ldots . . * x_{n} \mu_{R}\left(x_{1} * x_{2} \ldots . . * x_{n}\right) \cdot\left(x_{1} * x_{2} \ldots \ldots * x_{n}\right)
$$

\section{2-2 Properties Of Fuzzy Sets}

Fuzzy sets follow the same properties as crisp sets. Because of this fact and because the membership values of a crisp set are a subset of the interval $[0,1]$, classical sets can be thought of as special case of fuzzy sets. So fuzzy set properties are
Commutativity
$A \cup B=B \cup A$
$A \cap B=B \cap A$
Associative
$A \cup(B \cup C)=(A \cup B) \cup C$
$A \cap(B \cap C)=(A \cap B) \cap C$
Distributivity

$$
\begin{aligned}
A \cup(B \cap C)=(A \cup B) & \cap(A \cup C) \\
A & \cap(B \cup C)=(A \cap B) \cup(A \cap C)
\end{aligned}
$$


Identity

$$
\begin{aligned}
\mathrm{A} \cup \phi=\underset{\sim}{A} \quad \text { and } \mathrm{A} \cap \mathrm{x}=\mathrm{A} \\
\mathrm{A} \cap \phi=\phi \quad \text { and } \mathrm{A} \cup \mathrm{x}=\mathrm{x}
\end{aligned}
$$

\section{2-3 Methodologies:}

It is important to have a good design methodology for fuzzy systems because it is new for most designers. All fuzzy models tend to follow the design cycle explained in Fig.1. The methodology of fuzzy logic controller attempts to formalize and structure a procedure in which the conceptual design is done on paper. The last step is an iterative cycle where modeling and simulation are carried out on a computer

using fuzzy logic development tools and continued until the model behaves as desired.

\section{3 - FUZZY CONTROL SCHEME}

Generally the design of fuzzy controllers is based on the operators understanding of the behavior of the process instead of its detailed mathematical model. several methods for rule extraction are encountered in the field of fuzzy logic. This paper applies a method which analyzes the combination of system and conventional controller .

The proposed algorithm is as follows :-

1- Analyse the system model and choose the control parameters as the angle and the angle derivative.

2- A critical damped system is required for the satellite model, therefore it is difficult to observe the change in output (torque) with respect to change of angle and angle derivative, thus the system is modified to have damping coefficient equal to 0.7 ( $\xi=.07)$.

3- The system input excitation and output response are sampled

4- From these samples the boundaries of the membership function of angle, angle derivative and controller output are specified (there is no general method for this )

5- From the input and output curves and the corresponding membership function construct the rule base in the form of IF-THEN rules.

6- Apply Mamdani min-max reasoning algorithm to get desired output from the set of rules .

7- Finally make defuzzification using center of gravity method to convert fuzzy output into crisp output .

\section{3-2 Justification Of Fuzzy Control Rules}

The method used in this paper is a heuristic method in which a collection of fuzzy control rules is formed by analyzing the behavior of the controlled process [4],[5]. 
The control rules are derived in such a way that the deviation from a desired state can be corrected and the control objective can be achieved. Mamdani [11] proposed a prescriptive algorithm for deriving the " best " control rules by restricting system responses to " a prescriptive fuzzy band" which is specified by fuzzy control rules. However, the convergence of the prescriptive method requires a careful analysis.

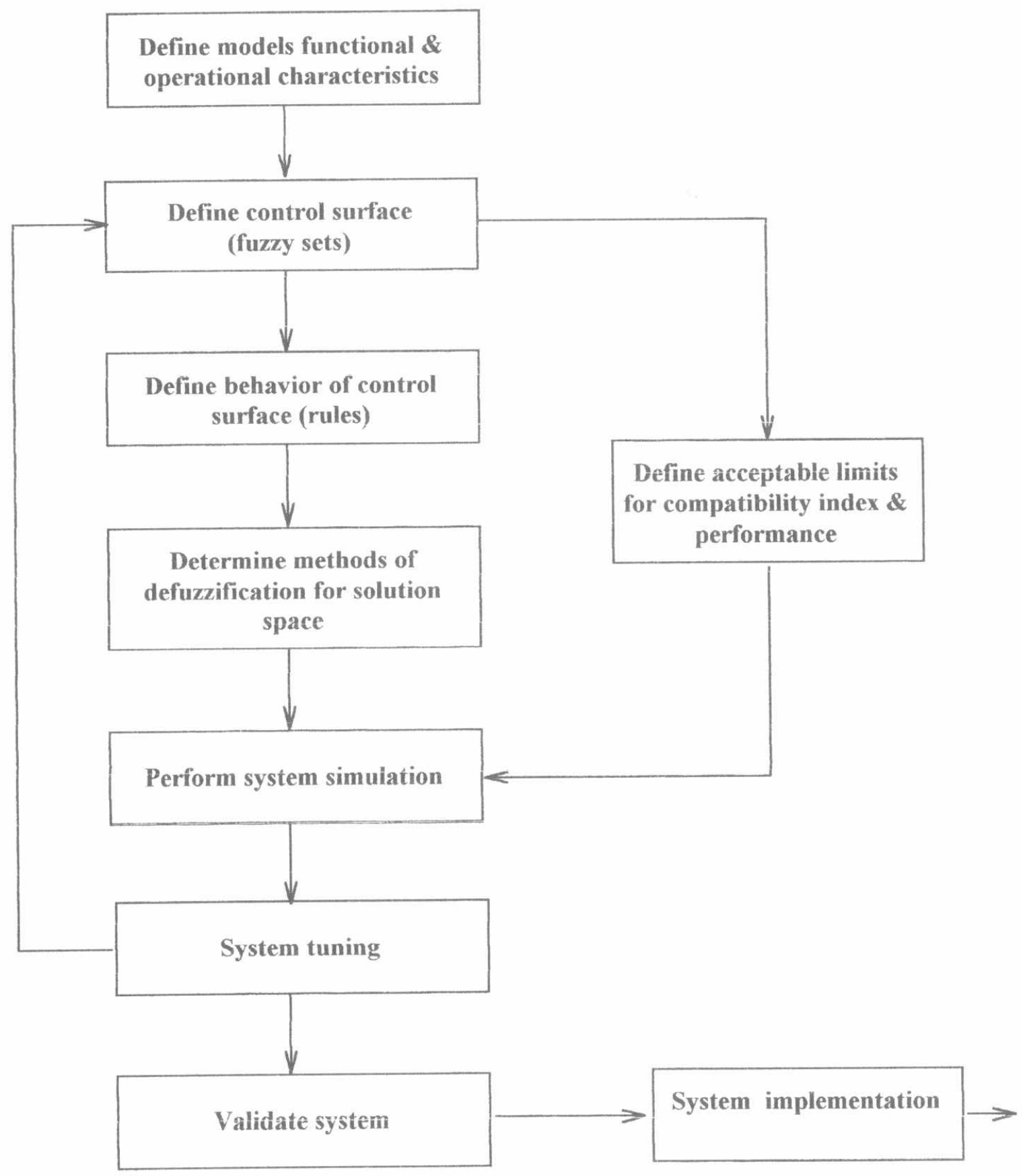

Fig. 1 Flowchart of fuzzy logic development projects 
King and Mamdani [12] introduced another useful method for rule justification called "scale mappings ". The rule justification is done by referring to a closed system trajectory in the phase plane. Acknowledgement of parameter adjusting based on phase plane analysis ( e.g. overshoot, rise time) and an intuitive feel for the behavior of the closed loop system are required.

Fig $2 \& 3 \& 4$ show the pitch axis control response of the three axis stabilization satellite in case of conventional controller, where the input variable is angle and angle derivative and the output variable is the momentum torque.

Assume that the sets of input/output variables have the same number and name \{negative, zero, positive\}. Thus the prototype of fuzzy control rules is tabulated in table 1 and a justification of fuzzy control rule is added in table 2.

Table 1 Prototype of fuzzy control rules with term sets

\begin{tabular}{ccccc}
\hline Rule No. & Theta & Thetadot & Torque & $\begin{array}{c}\text { Reference } \\
\text { point }\end{array}$ \\
1 & $\mathrm{P}$ & $\mathrm{Z}$ & $\mathrm{P}$ & $\mathrm{a}, \mathrm{e}, \mathrm{i}$ \\
2 & $\mathrm{Z}$ & $\mathrm{N}$ & $\mathrm{N}$ & $\mathrm{b}, \mathrm{f}, \mathrm{j}$ \\
3 & $\mathrm{~N}$ & $\mathrm{Z}$ & $\mathrm{N}$ & $\mathrm{c}, \mathrm{g}, \mathrm{k}$ \\
4 & $\mathrm{Z}$ & $\mathrm{P}$ & $\mathrm{P}$ & $\mathrm{d}, \mathrm{h}$ \\
5 & $\mathrm{Z}$ & $\mathrm{Z}$ & $\mathrm{Z}$ & set point \\
\hline
\end{tabular}

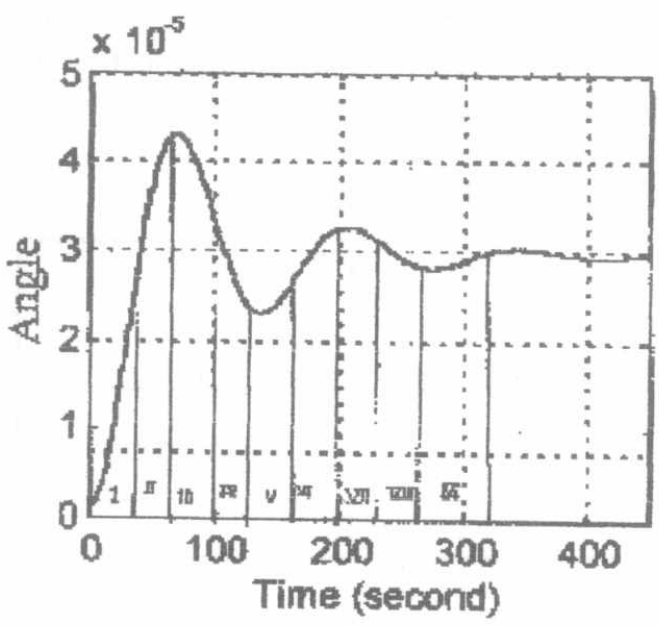

Fig 2 Time response of pitch



Fig 3 Time response of pitch angle derivative 


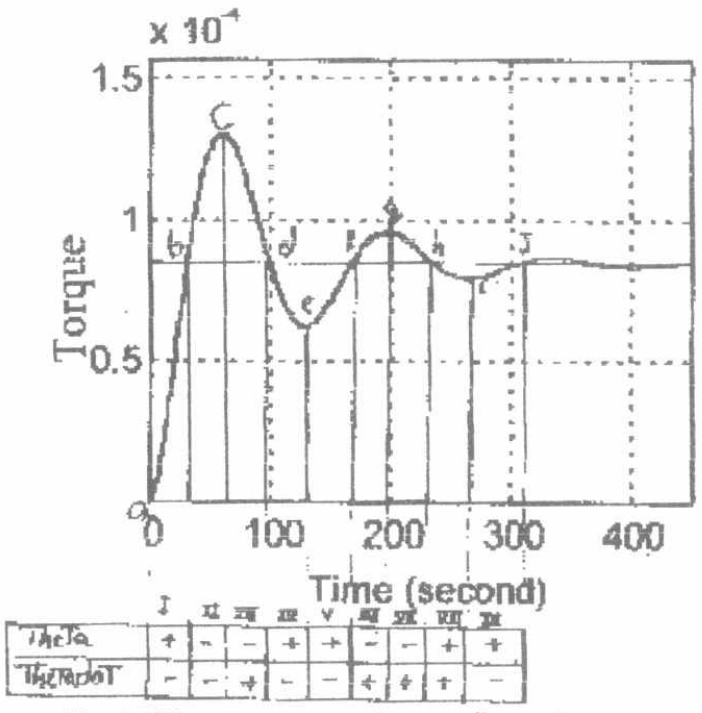

Fig 4 Fime resportse of contraller output

Table 2 Rule justification with term sets

$\begin{array}{crrrc}\text { Rule No. } & \text { Theta } & \text { Thetadot } & \text { Torque } & \text { Reference range } \\ 6 & \mathrm{P} & \mathrm{N} & \mathrm{P} & \text { i (rise time), } \mathrm{v} \\ 7 & \mathrm{~N} & \mathrm{~N} & \mathrm{~N} & \text { ii (overshoot), vi } \\ 8 & \mathrm{~N} & \mathrm{P} & \mathrm{N} & \text { iii, vii } \\ 9 & \mathrm{P} & \mathrm{P} & \mathrm{P} & \text { iv, viii } \\ 10 & \mathrm{P} & \mathrm{N} & \mathrm{Z} & \text { ix }\end{array}$

The lookup table is extracted and is shown in table 3. Better control performance can be obtained by using finer fuzzy partitioned subspaces for example the term set $\{N B, N M, N S, Z E, P S, P M, P B\}$ yields a new lookup table shown in table 4.

Table 3 Look up table for the desired fuzzy controller

\begin{tabular}{|c|c|c|c|}
\hline$\because \theta^{\circ}$ & $\mathrm{NE}$ & ZE & PS \\
\hline NE & $\mathrm{N}$ & $\mathrm{N}$ & Z \\
\hline ZE & $\mathrm{N}$ & $Z$ & $\mathrm{P}$ \\
\hline PS & Z & $\mathrm{P}$ & $P$ \\
\hline
\end{tabular}


Proceedings of the $2^{\text {nd }}$ ICEENG conference, 23-25 Nov. 1999

\begin{tabular}{|l|c|}
\hline RG-11 & 8 \\
\hline
\end{tabular}

Table 4 Lookup table of expanded fuzzy sets

\begin{tabular}{|c|c|c|c|c|c|}
\hline$\because \ddots{ }^{\ddots} \cdot$ & NBD & NSd & Zod & PSd & PBd \\
\hline PB & ZOF & PSF & PBF & PBF & PBF \\
\hline PS & NSF & ZOF & PSF & PBF & PBF \\
\hline ZO & NBF & NSF & ZOF & PSF & PBF \\
\hline NS & NBF & NBF & NSF & ZOF & PSF \\
\hline NB & NBF & NBF & NSF & NSF & ZOF \\
\hline
\end{tabular}

\section{3-3 Pitch Axis Control}

A triangular membership function is considered, we construct fuzzy logic controller, insert it in the feedback path with the open loop system describing the pitch planemotion described in [8], where the open loop transfer function is

$$
\mathrm{G}(\mathrm{S})=\frac{1}{1360 \mathrm{~S}^{2}}
$$

The overall block diagram is shown in Fig.5. The time response of angle and torque for both fuzzy controller and classical controller is shown in Fig.6, Fig.7 From these results the output of the fuzzy controller is not satisfactory because of the existance of the overshoot in the output response of the pitch angle.

Another design configuration is done using another type of membership function which is selected as gaussian shape The output of this fuzzy controller configuration is shown in Fig. 1-8, Fig. 1-9 which consists of the time response of pitch angle and moment torque of both classical and fuzzy controller.

It is clear that the response of the fuzzy controller is good since criticaly damped smooth response is needed. This is achieved by using gaussin shape membership function providing smooth changes, but of course slower response than triangular.

For the new design configuration $\frac{\theta(s)}{M(s)}=\frac{1}{\mathrm{I}_{\mathrm{yy}}\left(s+\sqrt{\frac{k_{\theta}}{I_{Y Y}}}\right)^{2}}$

For step disturbance solar pressure $M(s)=M / s$ and $M$ is expected to be $8.5 \times 10^{-5}$ so $\theta_{s s}=\frac{8.5 \times 10^{-5}}{1.41}$

From Fig 8 it is clear that fuzzy controller has better transient and steady state response than classical controller. 


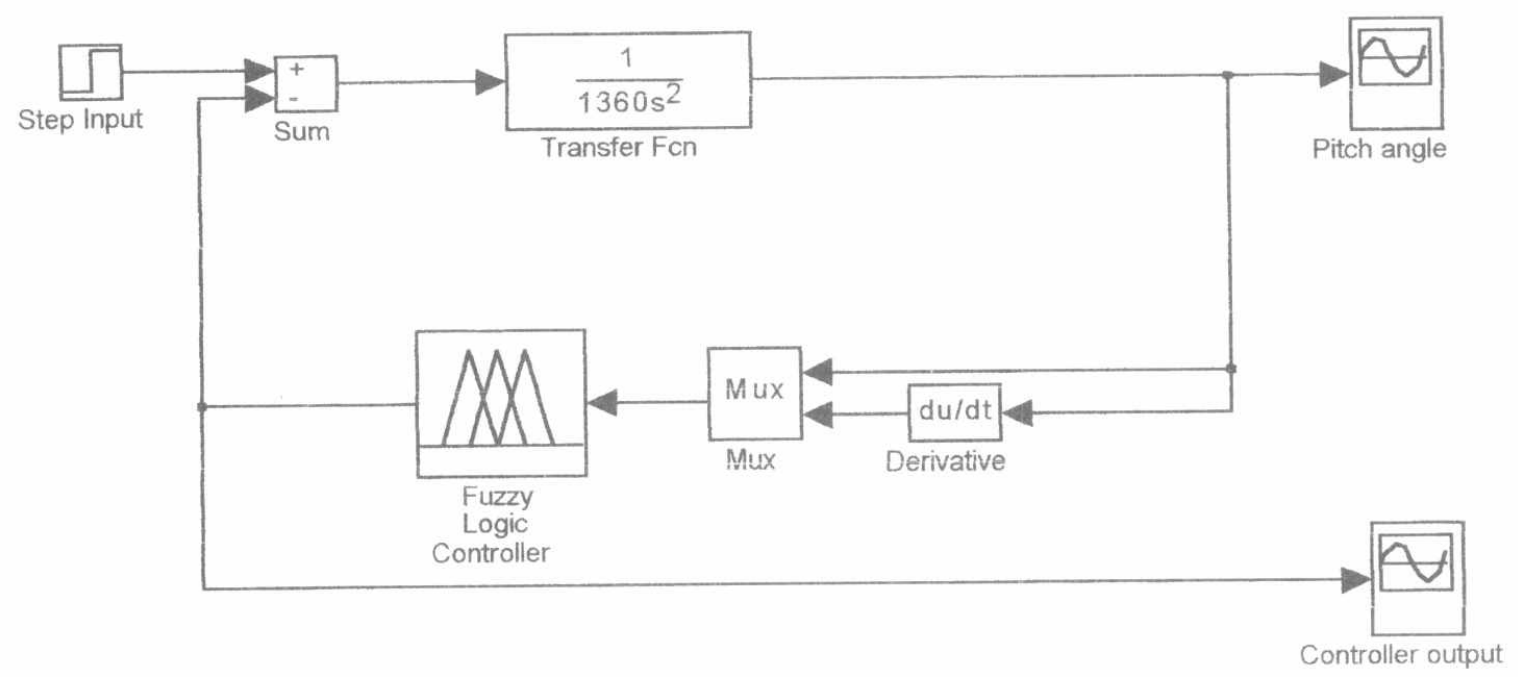

Fig. 5 Block diagram of pitch axis control

\section{3-4 Roll /yaw Axis Controller}

The same strategy for obtaining the lookup table for pitch channel is used, and the lookup table of roll/yaw channel is as shown in table- 5

The open loop transfer function of roll / yaw channel is

$$
G(s)=\frac{2200 s^{2}+2.54 \times 10^{-3}}{594 \times 10^{4} s^{2}+1237.4 s^{2}+6.4516 \times 10^{-6}}
$$

From lookup table-5 the rule is extracted and a new fuzzy controller is built using a gaussin shape membership function. through try and error the width of membership function is chosen. The time responses of fuzzy controller are shown in Fig.10 \& Fig.11 for pitch angle and moment respectively.

\section{4- CONCLUSION}

The investigation of the results of conventional and fuzzy controllers for the three axis stabilization satellite indicates that :

- The conventional controller has a specify design procedure while there is no specific method to validate the design of the rule-based system.

- Subsets in fuzzy logic must be defined over all regions of operation, otherwise there is an instant at which controller output is undesirable. 
Proceedings of the $2^{\text {nd }}$ ICEENG conference, 23-25 Nov. 1999

\begin{tabular}{|l|l|}
\hline $\mathrm{RG}-\mathrm{Il}$ & 10 \\
\hline
\end{tabular}

- The time response of rule-based controllers is better than conventional controllers.

- The fuzzy logic controller is more robust due to change in disturbance torque level.

- The fuzzy logic controller is less sensitive to high frequency signal noise and exhibits better results.

However several drawbacks were encountered :

- The fuzzy controller has exponential increase of control rules with the increase of the number of control inputs and term set, leading to more complex systems.

-Another drawback is the derivation of control rule -which is the most important part has no general rules.

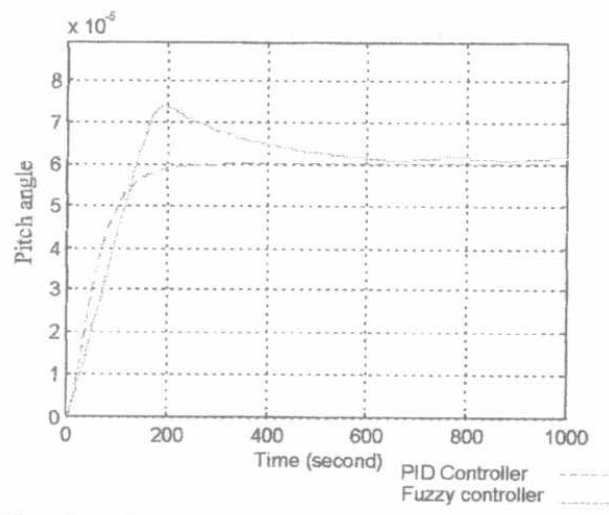

Fig 6 Time response of pitch angle

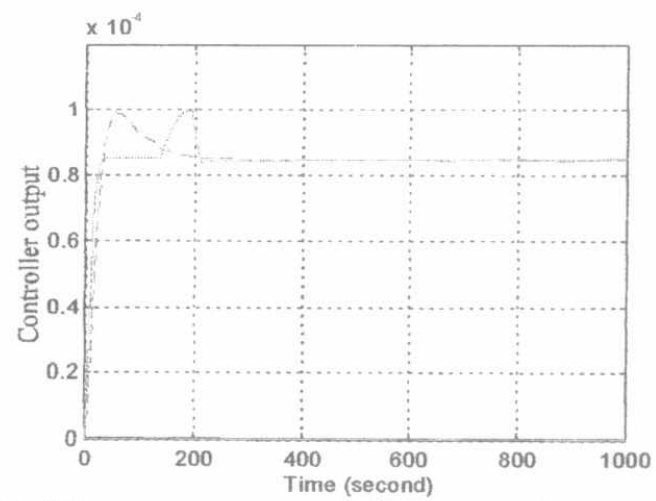

Fig. 7 Time response of the controller output

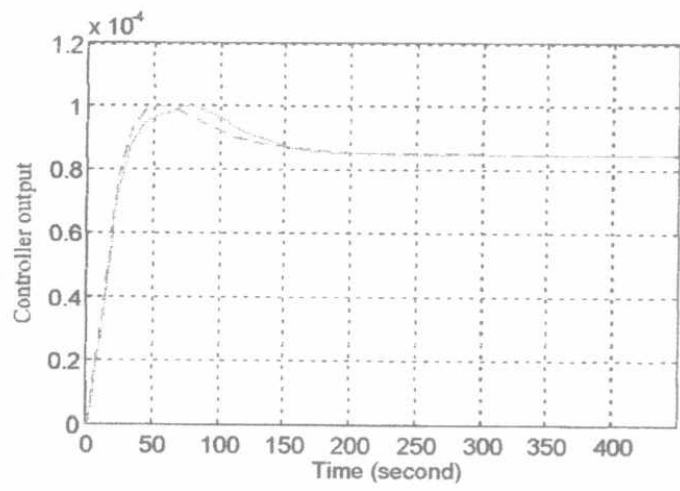

Fig. 9 Time response of the controller output 


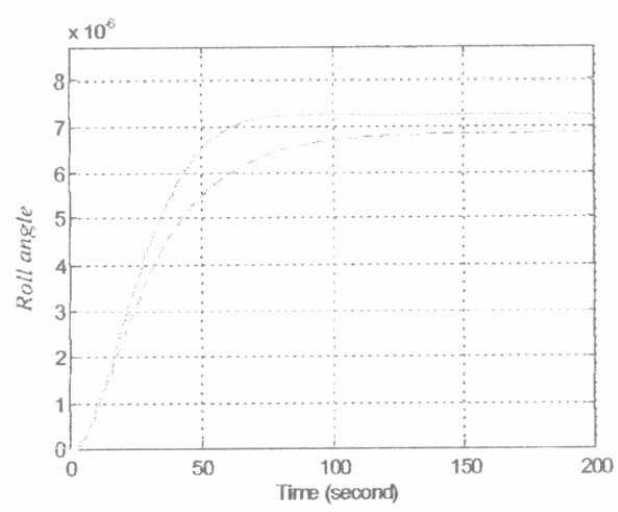

Fig. 10 Time response of the roll angle

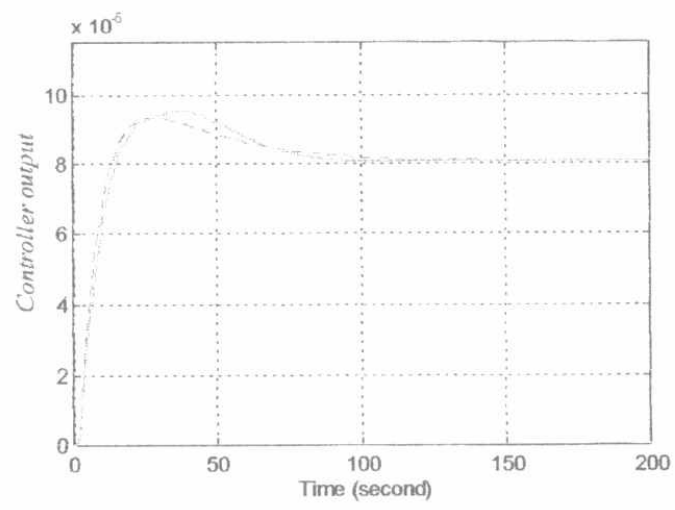

Fig. 11 Time response of the controller output

\section{REFERENCES}

[1] A.E.Sabroff " advanced spacecraft stabilization and control techniques " journal of spacecraft and rockets, Vol. [5] No 12 p.1377-1393 Dec. 1968

[2] A.J. vanderwal "Application of fuzzy logic control in industry " fuzzy sets and systems Vol. [74] 1995 p.33-41

[3] B.N.Agrawal "Design of geosynchronous spacecraft " Printice -hall

[4] C.Chien lee "Fuzzy logic in control systems: fuzzy logic controller part I " IEEE transaction on systems, man and cybernetics Vol. 20 No.2 march / April 1990 .

[5] C.Chien lee " Fuzzy logic in control systems : fuzzy logic controller part II " IEEE transaction on systems, man and cybernetics Vol. 20 No.3 march / April 1990.

[6] C.W.De silva "intelligent control : fuzzy logic application" CRC press 1995

[7] F . Bouslama and A.Ichikawa " fuzzy control rules and their natural control laws " fuzzy sets and systems Vol. 481990 p. 65-86

[8] M.H.Kaplan " Modern spacecraft dynamics and control " John wiley \& sons

[9] M. Mizumoto " realization of PID controls by fuzzy control methods " fuzzy sets and system Vol. [70] 1995 p. 171-182 
Proceedings of the $2^{\text {nd }}$ ICEENG conference, 23-25 Nov. 1999

\begin{tabular}{|l|l|}
\hline RG-11 & 12 \\
\hline
\end{tabular}

[10] M.Sugeno, G.T.Kang " Structure identification of fuzzy model " Fuzzy sets and system vol. [28] 1988 pp. 15-33

[11] N.Baaklini, E.H.Mamdani "Prescriptive methods for driving control policy in a fuzzy logic controller" Electron. lett. ,Vol. [11] 1975 pp. 625-626 .

[12] P.J.King, E.H.Mamdani " Analysis of a fuzzy logic systems to industrial process " IFAC world congress, MIT, Boston, 1975.

[13] P.P. Iwens, A.W.Fleming and V.A.Spector " precision attitude control with a single body fixed momentum wheel " AIAA Mechanics and control of flight conference, 1974, p 79-89

[14] Robert lafore " C Programming using turbo c++ " The waite group,inc.

[15] T.J.Ross " fuzzy logic with engineering application " Mc Grawhill 1995

[16] J. Bukley " Theory of fuzzy controller : an introduction " fuzzy sets and system Vol. [51] 1992 p. 249-258. 
